\title{
Overview on intestinal transplantation: indications, techniques, outcomes, major advancements and future prospectives
}

\author{
D. Coco $^{1}$, S. Leanza ${ }^{2}$ \\ ${ }^{1}$ Department of General Surgery, Ospedali Riuniti Marche Nord, Pesaro, Italy, \\ ${ }^{2}$ Department of General Surgery, Carlo Urbani Hospital, Jesi, Ancona, Italy

\section{Трансплантація кишечника: показання, методи, результати, основні досягнення та перспективи}

\author{
Д. Коко ${ }^{1}$, С. Леанза ${ }^{2}$ \\ ${ }^{1}$ Лікарня Марке Норд, м. Пезаро, Італія, \\ Лікарня Карло Урбані, м. Єсі, Анкона, Італія
}

\section{Introduction}

The gut plays a major role in the whole-body energy equilibrium and human wellness [1-3]. Disruption of gut homeostasis often leads to loss of energy balance with development of life-threatening complications [4]. Intestinal transplantation has evolved from a rare therapeutic modality to a currently life-saving armamentarium for a subset of patients with intestinal failure in whom continuing treatment with intravenous nutrition had become impossible because of end-stage loss of venous access or end-stage liver disease [5].

The field of intestine transplantation is small with only 106 intestine transplants performed in the United States in 2012 at 18 active centers. This represents a decline from a high of 198 intestine transplants in 2007 and a substantially smaller volume compared to all other types of solid organ transplantation [6]. In contrast to the decline in volume in the United States, the volume of intestine transplantation over a 5-year period ending in 2012 increased substantially in South America and Europe. In addition, although the overall volume to date remains less than 50 cases, there has been a substantial increase in the number of centers that have initiated small bowel transplant programs in China and Japan [7]. Due to the small volume of transplants and paucity of centers i.e. only 47 centers worldwide currently active that perform this difficult and rare transplant many individuals outside and even within the medical field are unaware of the indications for intestine transplantation, current outcomes and recent advances [7]. This lack of awareness may have contributed to the decline in the frequency of intestine transplantation in recent years by limiting access to or referral for this lifesaving therapy. Hence, in this narrative review we aimed to recapitulate the current scenario of intestine transplantation including the indications, techniques used, outcomes, major advances, and future prospective on intestinal transplantation.

\section{Brief History of Intestinal Transplantation}

The history of intestinal transplantation begins with Alexis Carrel and his description of a method for performing vascular anastomosis. His initial articles demonstrate his bold yet logical approaches to both the technical and theoretical aspects of organ transplantation [8]. Carrel's technical basis for vascular anastomoses, proposed in 1902, is still valid for all solid organ transplantations, and is based on three main pillars: a) three stitches to change the cylindrical shape of the cut surface of vessels into a triangle; b) everting anastomosis; and c) use of very thin suture needles.

Lillehei et al reported the first canine model of isolated intestinal transplantation in 1959 [9]. This was an important landmark in the modern area of intestinal transplantation, because it was the first time that autographs and allografts were preserved by immersion in iced saline; after orthotopic reimplantation the autografts presented good functional capability. The following year, Starzl and Kaupp described a multivisceral transplantation technique in dogs in which the small bowel was transplanted as a composite of abdominal organs. The grafts included the liver, pancreas, stomach, intestine, and colon. Two central arteries, the celiac axis and the superior mesenteric in continuity with the aorta, were joined to the recipient's infrarenal aorta [10]. These two studies, along with a small animal experiment by Monchik and Russel, paved the way for investigations of problems related to intestinal transplantation, such as immunology, immunosuppression, graft preservation, metabolic events, and graft function [11].

\section{Indications and Contraindications to Intestinal Transplantation Indications:}

The most common reason for intestinal and multivisceral transplantation is small bowel syndrome which is the 


\section{Indications for Intestinal Transplantation}

\section{Failure of Parenteral Nutrition}

i. Impending (total bilirubin 3-6 mg/dL, progressive thrombocytopenia and progressive splenomegaly) or overt liver failure (portal hypertension, hepatosplenomegaly, hepatic fibrosis or cirrhosis) because of parenteral nutrition-liver injury.

ii. Central venous catheter-related thrombosis of 2 central veins.

iii. Frequent central line sepsis: 2 episodes/year of systemic sepsis secondary to line infections requiring hospitalization; a single episode of line-related fungemia; septic shock or acute respiratory distress syndrome.

iv. Frequent episodes of severe dehydration despite intravenous fluid in addition to parenteral nutrition.

High risk of death attributable to the underlying disease

i. Desmoid tumors associated with familial adenomatous polyposis.

ii. Congenital mucosal disorders (e.g. microvillus atrophy and intestinal epithelial dysplasia).

iii. Ultra-short bowel syndrome (gastrostomy, duodenostomy, residual small bowel $10 \mathrm{~cm}$ in infants and $20 \mathrm{~cm}$ in adults).

Intestinal failure with high morbidity or low acceptance of parenteral nutrition

i. Intestinal failure with high morbidity (frequent hospitalization, narcotic dependency) or inability to function (e.g. pseudo-obstruction, high output stoma).

ii. Patient's unwillingness to accept long-term parenteral nutrition (e.g. young patients).
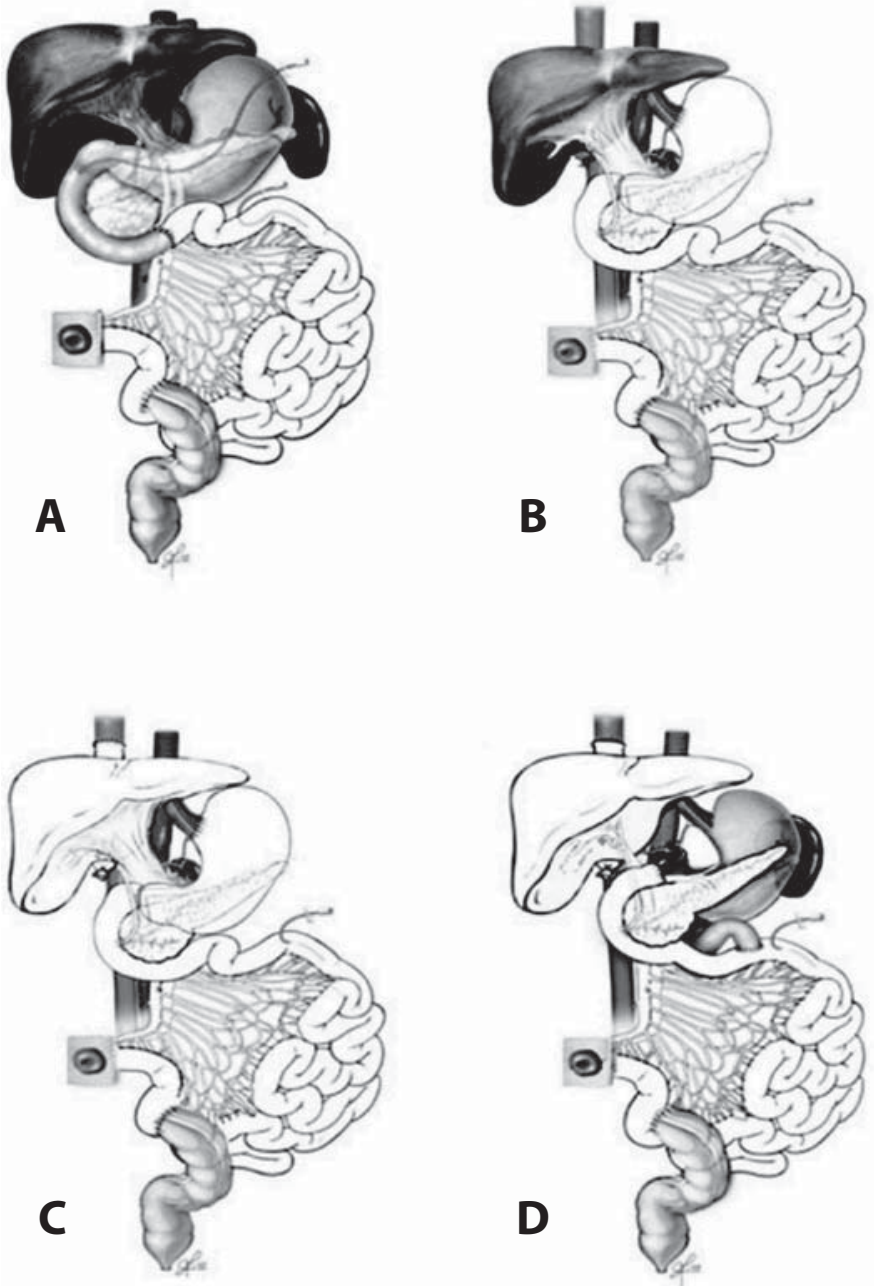

Figure 1

Techniques in Intestinal Transplantation,

$[A]$ Intestine alone, [B] Modified multivisceral transplant with exclusion of the liver, [C] Full multivisceral transplant that includes stomach, duodenum, pancreas, intestine and liver. [D] Combined liver and intestine with pancreas. Source: S. Bharadwaj et al 2017 [18]. leading cause of intestinal failure. Despite the significant improvement in patient survival, the procedure is still limited to patients who have experienced significant complications of parenteral nutrition and/or repeated nutritional failure with dehydration or electrolyte imbalance. Most physicians also require failed attempts at gut rehabilitation prior to referring patients to transplant centers[12]. The indications for intestinal transplantation approved by the Centers for Medicare and Medicaid services for reimbursement are listed in Table [13]. A 3-year prospective study that evaluated these approved indications concluded that intestinal transplantation is an appropriate life-saving measure for intestinal failure patients after failure of parenteral nutrition therapy [14]. Of note, European prospective data further suggested that recurrent infection may not be associated with definitive parenteral nutrition failure and may not warrant transplantation [15]. In addition, because of the current lack of effective rehabilitative surgery for disorders such as certain enterocyte dysfunction, gut dysmotility and Gardner syndrome, early transplantation may be necessary. Regardless of the indications for transplant, recently published data have stressed the importance of early transplantation, perhaps prior to overt parenteral nutrition-induced liver disease and possibly within one-year of use of pre-transplant parenteral nutrition for better survival [16].

\section{Contraindications}

An active systemic infection, whether bacterial or fungal, poses the most serious threat to survival of the patient in the early postoperative period. The pre-existence of severe neurologic dysfunction and malignancy are obvious preclusions. Individuals with a prior treated malignancy with an appropriate follow-up period, and having been cleared of recurrence by oncological evaluation, should not represent an absolute exclusion. Cardiac dysfunction, acute or chronic, may also be a contraindication; however, a thorough evaluation will determine whether transplantation can proceed safely. The age of the patient is not a usual limitation, how- 
Figure 2.

(A) The isolated small bowel graft consists of the entire jejunum and ileum. The arterial inflow is supplied by the superior mesenteric artery and the superior mesenteric vein drains the isolated small bowel graft. (B) In the small bowel allograft recipient, gastrointestinal continuity is re-established by anastomosis of the proximal native and donor jejunum and the distal bowel is brought out as a Bishop-Koop (shown) or loop ileostomy with (shown) or without anastomosis to the remnant native colon

Adapted from D. Sudan 2014 [24].

ever the overall health of the patient, including nutritional status, are of importance in the patient's ability to tolerate transplantation [17].

Techniques in Intestinal Transplantation

The type of technique used in intestinal transplantation depends on the underlying etiology of intestinal failure, quality of native organs, presence/severity of liver disease and history of prior abdominal surgeries. Despite the variety of nomenclature in literature, fundamentally there are 4 types of techniques considered while intestinal transplantation. (i) isolated small bowel transplant, (ii) liver-small bowel transplant, (iii) multivisceral transplant, and (iv) modified multivisceral transplant as depicted in Figure 1 [18].

Post-transplant survival rates may be higher for combined liver/intestine recipients compared with isolated intestine recipients due to proven immunologic benefits of the liver [19-21]. However, most patients with small bowel syndrome, pseudo-obstruction and Gardner syndrome receive isolated intestinal or modified multivisceral transplantation [22]. Additionally, recent data have suggested that hepatic fibrosis may not be an absolute contraindication for isolated intestinal transplant as 4 patients with significant portal and centrilobular fibrosis had regression of their liver disease after intestine-only transplant [23].

The technique of intestine alone which typically includes the entire jejunum and ileum as depicted in Figure $2 A$. Transplantation of the intestine allograft alone as demonstrated in Figure $2 B$ is increasing in frequency and for the first time in 2009 exceeded the number of combined liver and intestine transplants [6].
The most common combination of organs included with the intestine allograft historically was the liver and pancreas; however, the frequency has declined from 68\% in 2007 to $39 \%$ of all intestine transplants in 2011 [6]. A widely used technique for combined liver, small bowel and pancreas allograft referred by various centers as a multi-visceral graft, composite graft or Omaha technique are to procure all these organs simultaneously from the donor and transplant them en bloc as shown in Figure $3 A$ and $B$ [25]. The advantage of the combined liver, small bowel and pancreas allograft is that no hilar dissection of the graft is needed and therefore, there are fewer risks for donor-related vascular or biliary complications [25]. Alternatively, the liver and intestine can be transplanted as individual organs, without the pancreas graft, which has the advantage that if the intestine allograft should develop severe rejection, it could potentially be removed without requiring re-transplantation of the liver [26].

In some centers, additional gastro intestinal organs including the stomach, duodenum and/or colon may be procured and transplanted in continuity with the intestine allograft with or without donor liver and/or pancreas (Figure 4) [27-30]. Early series had suggested that inclusion of the colon might increase the risk for infection, several recent single center series and a recent review challenge this long held assumption. In fact, inclusion of the colon has been reported in $20 \%$ of small bowel grafts over the past decade[7]. Not only has inclusion of the colon been reported to be safe, but it has been associated with a decrease in the water content in the stool leading to fewer episodes of dehydration 


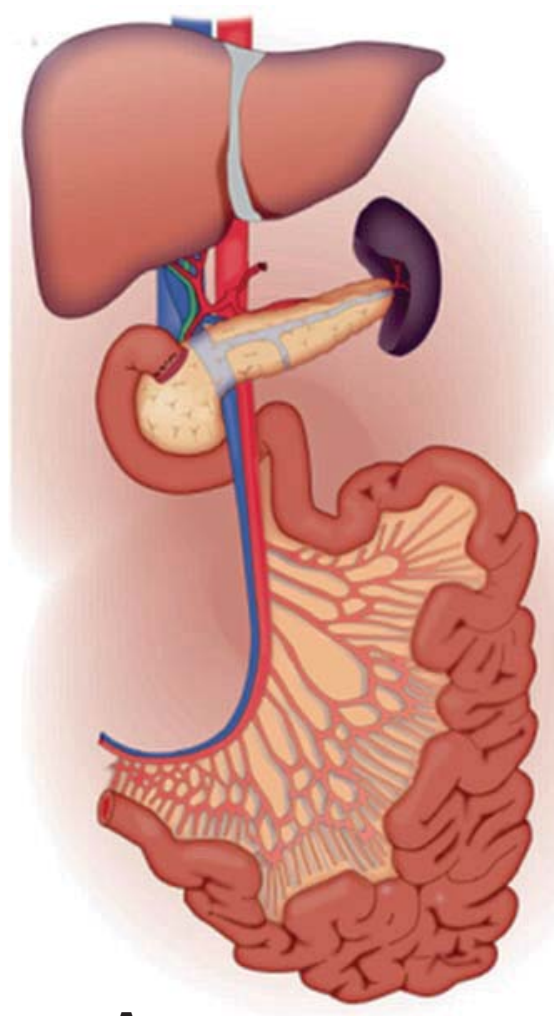

A
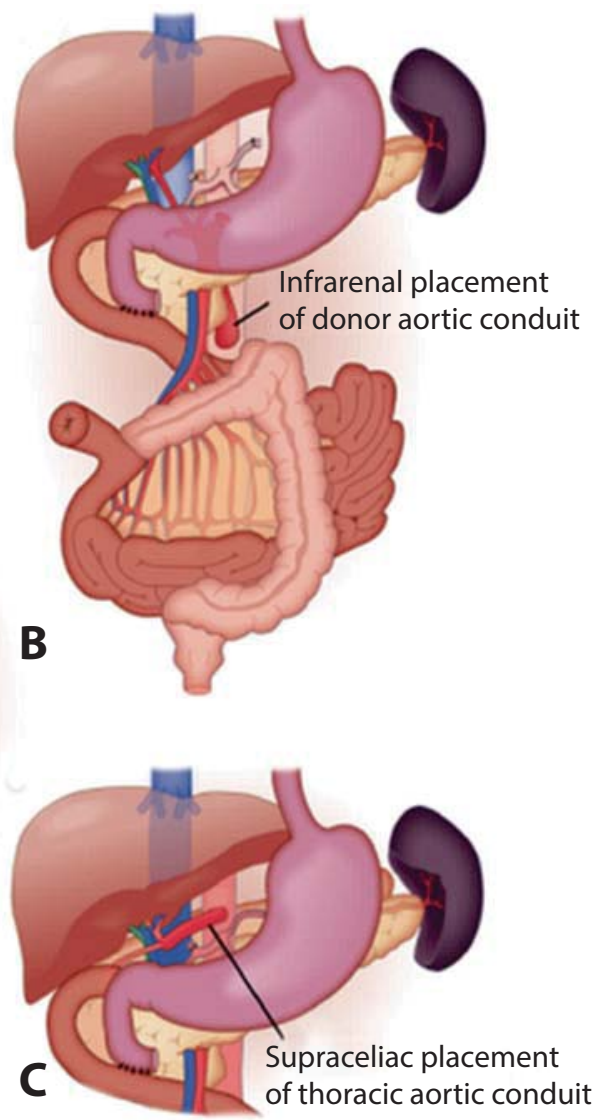

Figure 3.

(A) The combined liver, small bowel and pancreas allograft is usually procured en bloc without disruption of the hilar structures. The inflow is provided from the donor aorta in continuity to the celiac axis and superior mesenteric artery. The venous outflow is from the hepatic veins/donor vena cava. (B) In the liver, small bowel and pancreas recipient operation, the thoracic aortic conduit is attached to the infrarenal (shown) or suprarenal (see (C)) aorta and the caval anastomosis is done either in standard caval replacement or piggyback fashion. The bowel continuity is established between native and transplanted jejunum proximally and between donor ileum and native remnant colon distally. Adapted from D. Sudan 2014 [24].

and fewer hospital readmissions [6,31,32]. The inclusion of stomach with the allograft for patients with or without upper abdominal exenteration remains a center-specific decision with some centers applying it universally while others rarely or never including the stomach.

\section{Intestinal Transplantation - Outcomes Patient and graft survival}

A large series of 500 intestinal transplants demonstrated a direct, significant correlation between advancements in immunosuppression techniques and graft survival [19]. In particular, reduction in graft rejection, infection and renal failure have been credited for the decrease in mortality rates. However, these complications remain prominent and threatening to the long-term survival of graft function. In one study, the persistence of preformed and development of de-novo donor specific antibodies was credited as the most significant risk factor for graft survival [33]. Other significant predictors of long-term patient and graft outcome include personal social support as well as inclusion of liver for visceral allograft longevity. Recently, documented patient survival rates include $90 \%$ at 1 year, $75 \%$ at 10 years and $61 \%$ at 15 years. Overall graft survival rates were $59 \%$ and
$50 \%$ at 10 and 15 years, respectively [34]. Improvements in body mass index and high rates of certified nursing assistant reflect the substantial advancements in the field of intestinal and multivisceral transplantation. In patients who fail to achieve full recovery of allograft motility and function, ischemia reperfusion injury is thought to play a major role, although normothermic ex-vivo perfusion technology may reverse this unwanted effect [35].

Quality of life

Quality of life has become an essential endpoint for intestinal and multivisceral transplantation. Evidences revealed that non-functional social support and quality of life correlate directly with suboptimal patient survival $[36,37]$. Studies that have compared small intestinal transplantation to parenteral nutrition demonstrate that intestinal transplant patients reported significant improvement in quality of life, functional status, decreased anxiety and sleep difficulties compared with patients on parenteral nutrition $[38,39]$. In pediatric patients, the child health questionnaire study reported that transplant patients had physical and psychosocial functions comparable to their healthy counterparts. However, a recent study reported lower values in school 


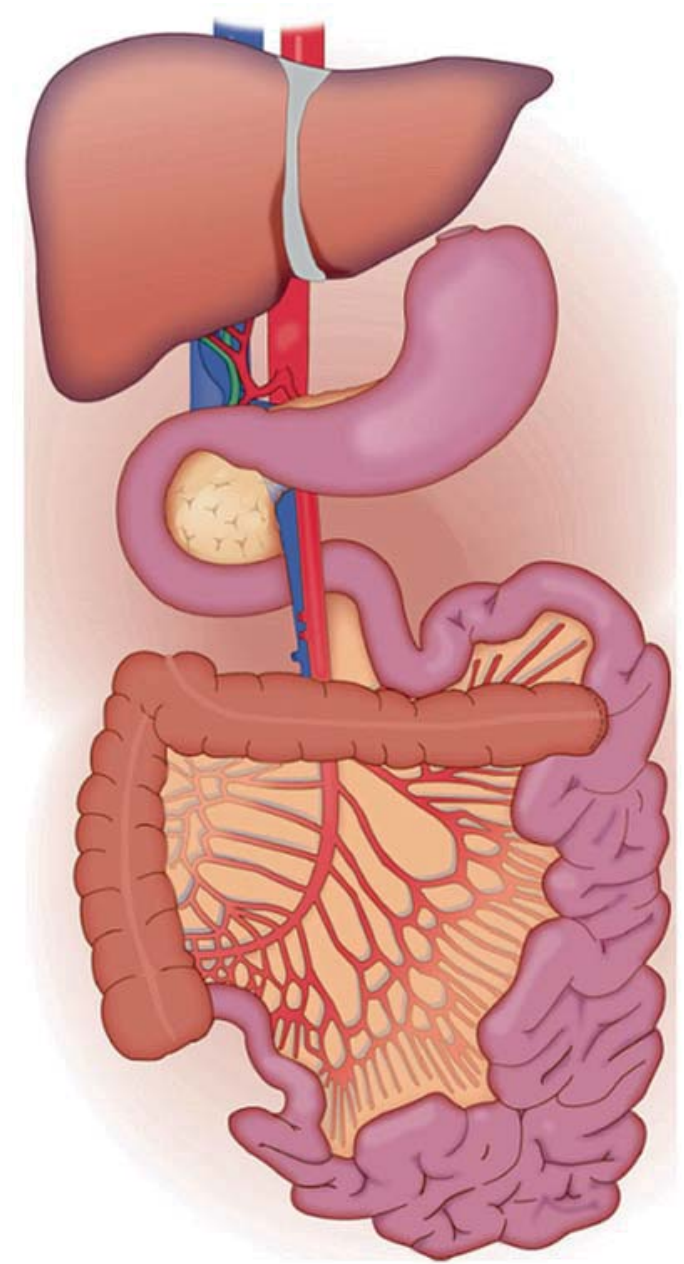

Figure 4.

The multi-visceral allograft is similar to the liver, small bowel and pancreas graft with the addition of the stomach and/or the colon in continuity. Adapted from D. Sudan 2014 [24].

functioning and psychological health using the Pediatric Quality of Life Inventory instrument [39].

\section{Advancements and Challenges}

Since last two decades there has been substantial advancements in improving both graft and patient survival as well as the quality of life of patients who undergo intestinal and multivisceral transplantation. However, despite these advancements, there are still challenges to be addressed are visceral allograft rejection, immunosuppression and immunological monitoring and long-term survivability. Many aspects of intestinal and multivisceral transplantation remains to be defined including biomarkers for early rejection, novel immunologic strategies and methods to reduce infectious complications.

The long-term survivability of both the grafts and the patients are dependent on the development of a multidisciplinary team including social assistance. These endeavours are particularly important for patients with lower socio-economic status and for pediatric recipients to reduce life threatening behaviours' including substance abuse and noncompliance. Monitoring of graft function, tumor surveillance and effective medical management of comorbidities are critical for sustaining long-term survivability. Furthermore, with studies indicating increased mortality rates in patients on the national waiting list, efforts to modify the existing United Network for Organ Sharing (UNOS)/ Organ Procurement and Transplantation Network (OPTN) allocation system and donor availability should be initiated for intestinal transplantation to further reduce rate of mortality of patients' with intestinal failure.

\section{Conclusions}

Clinical-nutritional autonomy is the ultimate goal of patients with intestinal failure. Outcome improvements in intestinal transplantation have added another dimension to the therapeutic armamentarium in the field of gut rehabilitation through relentless efforts in the standardization of surgical techniques, advancements in immunosuppressive therapies and induction protocols and improvement in postoperative patient care. Improved survival and quality of life as well as resumption of an oral diet should enable intestinal transplantation to be an important option for patients with intestinal failure in addition to continued rehabilitation. We recommend that early referral to intestinal and multivisceral transplantation for patients with intestinal failure will afford them the best opportunity to regain Clinical-nutritional autonomy. Hence, future efforts that use new or existing multisite registries to generate outcome data including measures of quality of life for intestinal failure with and without transplantation should provide answers to questions of timing for intestinal transplantation including preemptive transplant, with less risk of biases inherent to single-center studies. Furthermore, improving expertise in the management of intestinal failure has benefitted all patients including those who receive an intestinal allograft, but it remains essential that referral for transplantation should occur before the clinical problems that motivate referral become so serious that success of the operation is compromised. Future research should focus on detecting biomarkers of early rejection, enhanced immunosuppression protocols, improved postoperative care and early referral to transplant centers.

Funding. No source of funding has been received for this work. Autbors' contribution. All authors made the same contribution to this article.

competing interests. The authors have no conflict of interest.

Consent for publication. All authors approved the paper to be published.

\section{References}

1. Mithieux G. Nutrient control of energy homeostasis via gut-brain neural circuits. Neuroendocrinology. 2014;100(2-3):89-94. doi: 10.1159/000369070. Epub 2014 Oct 20. PMID: 25342450. 
2. Murphy KG, Bloom SR. Gut hormones and the regulation of energy homeostasis. Nature. 2006 Dec 14;444(7121):854-9. doi: 10.1038/ nature05484. PMID: 17167473.

3. Nieuwdorp M, Gilijamse PW, Pai N, Kaplan LM. Role of the microbiome in energy regulation and metabolism. Gastroenterology. 2014 May;146(6):1525-33. doi: 10.1053/j.gastro.2014.02.008. Epub 2014 Feb 19. PMID: 24560870.

4. Abu-Elmagd KM, Costa G, McMichael D, Khanna A, Cruz RJ, Parekh N, et al. Autologous Reconstruction and Visceral Transplantation for Management of Patients With Gut Failure After Bariatric Surgery: 20 Years of Experience. Ann Surg. 2015 Oct;262(4):586601. doi: 10.1097/SLA.0000000000001440. PMID: 26366538.

5 Wolfe RA, Ashby VB, Milford EL, Ojo AO, Ettenger RE, Agodoa LY, et al. Comparison of mortality in all patients on dialysis, patients on dialysis awaiting transplantation, and recipients of a first cadaveric transplant. N Engl J Med. 1999 Dec 2;341(23):1725-30. doi: 10.1056/NEJM199912023412303. PMID: 10580071.

6. Organ Procurement and Transplantation Network (OPTN) and Scientific Registry of Transplant Recipients (SRTR). OPTN/SRTR 2011 annual data report. Rockville, MD: Department of Health and Human Services, Health Resources and Services Administration, Healthcare Systems Bureau, Division of Transplantation, 2012.

7. ITR. 2013 bi-annual report. In: Grant D, eds. Intestinal Transplant Registry. Toronto, ON: Intestinal Transplant Association, 2014.

8. Carrel A. La Technique des anastomoses vasculaires et la transplantation des visceres. Lyon Med. 1902; 98:859-64.

9. Lillehei RC, Goott B, Miller FA. The physiological response of the small bowel of the dog to ischemia including prolonged in vitro preservation of the bowel with successful replacement and survival. Ann Surg. 1959 Oct;150(4):543-60. doi: 10.1097/00000658195910000-00001. PMID: 14416956; PMCID: PMC1613469.

10. Starzl TE, Kaupp HA Jr. Mass homotransplantation of abdominal organs in dogs. Surg Forum. 1960;11:28-30. PMID: 21566700; PMCID: PMC3091286.

11. Monchik GJ, Russell PS. Transplantation of small bowel in the rat: technical and immunological considerations. Surgery. 1971 Nov;70(5):693-702. PMID: 4399244.

12. Grant D, Abu-Elmagd K, Mazariegos G, Vianna R, Langnas A, Mangus R, et al. Intestinal transplant registry report: global activity and trends. Am J Transplant. 2015 Jan;15(1):210-9. doi: 10.1111/ ajt.12979. Epub 2014 Dec 1. PMID: 25438622.

13. Buchman AL, Scolapio J, Fryer J. AGA technical review on short bowel syndrome and intestinal transplantation. Gastroenterology. 2003 Apr;124(4):1111-34. doi: 10.1016/s0016-5085(03)70064-x. PMID: 12671904.

14. Pironi L, Forbes A, Joly F, Colomb V, Lyszkowska M, Van Gossum A, et al. Survival of patients identified as candidates for intestinal transplantation: a 3-year prospective follow-up. Gastroenterology. 2008 Jul;135(1):61-71. doi: 10.1053/j.gastro.2008.03.043. Epub 2008 Mar 26. PMID: 18471440.

15. Pironi L, Hébuterne X, Van Gossum A, Messing B, Lyszkowska M, Colomb V, et al. Candidates for intestinal transplantation: a multicenter survey in Europe. Am J Gastroenterol. 2006 Jul;101(7):163343; quiz 1679. doi: 10.1111/j.1572-0241.2006.00710.x. PMID: 16863571 .
16. Reyes J, Mazariegos GV, Bond GM, Green M, Dvorchik I, Kosmach-Park B, et al. Pediatric intestinal transplantation: historical notes, principles and controversies. Pediatr Transplant. 2002 Jun;6(3):193-207. doi: 10.1034/j.1399-3046.2002.02003.x. PMID: 12100503.

17. Khan K, Kumar V, Gruessner RWG. Liver and parenteral nutrition. In: Boyer T, Manns M, Sanyal AJ, editora. Zakim \& Boyer's: Hepatology: A Textbook of Liver Disease. Philadelphia: Elsevier Saunders; 2010.986-95. ISBN: 9781437708813.

18. Bharadwaj S, Tandon P, Gohel TD, Brown J, Steiger E, Kirby DF, et al. Current status of intestinal and multivisceral transplantation. Gastroenterol Rep (Oxf). 2017 Feb;5(1):20-28. doi: 10.1093/ gastro/gow045. Epub 2017 Jan 26. PMID: 28130374; PMCID: PMC5444259.

19. Abu-Elmagd KM, Costa G, Bond GJ, Soltys K, Sindhi R, Wu T, et al. Five hundred intestinal and multivisceral transplantations at a single center: major advances with new challenges. Ann Surg. 2009 Oct;250(4):567-81. doi: 10.1097/SLA.0b013e3181b67725. PMID: 19730240.

20. Nishida S, Levi D, Kato T, Nery JR, Mittal N, Hadjis N, et al. Ninety-five cases of intestinal transplantation at the University of Miami. J Gastrointest Surg. 2002 Mar-Apr;6(2):233-9. doi: 10.1016/ s1091-255x(01)00073-7. PMID: 11992809.

21. Ueno T, Fukuzawa M. Current status of intestinal transplantation. Surg Today. 2010 Dec;40(12):1112-22. doi: 10.1007/s00595-0104324-y. Epub 2010 Nov 26. PMID: 21110153.

22. Cruz RJ, Costa G, Bond G, Soltys K, Stein WC, Wu G, et al. Modified "liver-sparing" multivisceral transplant with preserved native spleen, pancreas, and duodenum: technique and long-term outcome. J Gastrointest Surg. 2010;14(11):1709-21. doi.org/10.1007/ s11605-010-1317-5.

23. Fiel MI, Sauter B, Wu HS, Rodriguez-Laiz G, Gondolesi G, Iyer $\mathrm{K}$, et al. Regression of hepatic fibrosis after intestinal transplantation in total parenteral nutrition liver disease. Clin Gastroenterol Hepatol. 2008 Aug;6(8):926-33. doi: 10.1016/j.cgh.2008.04.011. PMID: 18674734.

24. Sudan D. The current state of intestine transplantation: indications, techniques, outcomes and challenges. Am J Transplant. 2014 Sep;14(9):1976-84. doi: 10.1111/ajt.12812. Epub 2014 Aug 6. PMID: 25307033.

25. Sudan DL, Iyer KR, Deroover A, Chinnakotla S, Fox IJ Jr, Shaw $\mathrm{BW} \mathrm{Jr}$, et al. A new technique for combined liver/small intestinal transplantation. Transplantation. 2001 Dec 15;72(11):1846-8. doi: 10.1097/00007890-200112150-00025. PMID: 11740401.

26 Fishbein T, Florman S, Gondolesi G, Decker R. Noncomposite simultaneous liver and intestinal transplantation. Transplantation. 2003 Feb 27;75(4):564-5. doi: 10.1097/01.TP.0000045711.68765.84. PMID: 12605130.

27. Grant D, Abu-Elmagd K, Reyes J, Tzakis A, Langnas A, Fishbein T, et al. 2003 report of the intestine transplant registry: a new era has dawned. Ann Surg. 2005 Apr;241(4):607-13. doi: 10.1097/01.sla.0000157265.85388.a1. PMID: 15798462; PMCID: PMC1357064.

28. Mangus RS, Tector AJ, Kubal CA, Fridell JA, Vianna RM. Multivisceral transplantation: expanding indications and improving 
outcomes. J Gastrointest Surg. 2013 Jan;17(1):179-86; discussion p.186-7. doi: 10.1007/s11605-012-2047-7. Epub 2012 Oct 16. PMID: 23070622.

29. Mazariegos GV, Steffick DE, Horslen S, Farmer D, Fryer J, Grant D, et al. Intestine transplantation in the United States, 1999-2008. Am J Transplant. 2010 Apr;10(4 Pt 2):1020-34. doi: 10.1111/j.16006143.2010.03044.x. PMID: 20420650.

30. Kato T, Ruiz P, Thompson JF, Eskind LB, Weppler D, Khan FA, et al. Intestinal and multivisceral transplantation. World J Surg. 2002 Feb;26(2):226-37. doi: 10.1007/s00268-001-0210-5. Epub 2001 Dec 21. PMID: 11865353.

31. Kato T, Selvaggi G, Gaynor JJ, Takahashi H, Nishida S, Moon J, et al. Inclusion of donor colon and ileocecal valve in intestinal transplantation. Transplantation. 2008 Jul 27;86(2):293-7. doi: 10.1097/ TP.0b013e31817ef01c. PMID: 18645493.

32. Matsumoto CS, Kaufman SS, Fishbein TM. Inclusion of the colon in intestinal transplantation. Curr Opin Organ Transplant. 2011 Jun;16(3):312-5. doi: 10.1097/MOT.0b013e3283467102. PMID: 21467934.

33. Matsumoto CS, Kaufman SS, Fishbein TM. Inclusion of the colon in intestinal transplantation. Curr Opin Organ Transplant. 2011 Jun;16(3):312-5. doi: 10.1097/MOT.0b013e3283467102. PMID: 21467934 .

34. Abu-Elmagd KM, Kosmach-Park B, Costa G, Zenati M, Martin L, Koritsky DA, et al. Long-term survival, nutritional autonomy, and quality of life after intestinal and multivisceral transplantation. Ann Surg. 2012 Sep;256(3):494-508. doi: 10.1097/SLA.0b013e318265f310. PMID: 22868368.
35. Boehnert MU, Yeung JC, Bazerbachi F, Knaak JM, Selzner N, McGilvray ID, et al. Normothermic acellular ex vivo liver perfusion reduces liver and bile duct injury of pig livers retrieved after cardiac death. Am J Transplant. 2013 Jun;13(6):1441-9. doi: 10.1111/ ajt.12224. Epub 2013 May 13. PMID: 23668775.

36. Golfieri L, Lauro A, Tossani E, Sirri L, Venturoli A, Dazzi A, et al. Psychological adaptation and quality of life of adult intestinal transplant recipients: University of Bologna experience. Transplant Proc. 2010 Jan-Feb;42(1):42-4. doi: 10.1016/j.transproceed.2009.12.021. PMID: 20172278.

37. O'Keefe SJ, Emerling M, Koritsky D, Martin D, Stamos J, Kandil $\mathrm{H}$, et al. Nutrition and quality of life following small intestinal transplantation. Am J Gastroenterol. 2007 May;102(5):1093-100. doi: 10.1111/j.1572-0241.2007.01125.x. Epub 2007 Mar 22. PMID: 17378906.

38. DiMartini A, Rovera GM, Graham TO, Furukawa H, Todo S, Funovits M, et al. Quality of life after small intestinal transplantation and among home parenteral nutrition patients. JPEN J Parenter Enteral Nutr. 1998 Nov-Dec;22(6):357-62. doi: 10.1177/0148607198022006357. PMID: 9829608.

39. Ngo KD, Farmer DG, McDiarmid SV, Artavia K, Ament ME, Vargas J, et al. Pediatric health-related quality of life after intestinal transplantation. Pediatr Transplant. 2011 Dec;15(8):849-54. doi: 10.1111/j.1399-3046.2011.01590.x. PMID: 22112001.

Received: 29.12.2020 